\title{
High heat flux tests of the WENDELSTEIN 7-X pre-series target elements Experimental evaluation of the thermo-mechanical behaviour
}

\author{
H. Greuner ${ }^{\text {a,* }}$, B. Boeswirth ${ }^{\text {a }}$, J. Boscary ${ }^{a}$, A. Plankensteiner ${ }^{b}$, B. Schedler ${ }^{b}$ \\ ${ }^{\mathrm{a}}$ Max-Planck-Institut für Plasmaphysik, Euratom Association, Boltzmannstr. 2, D-85748 Garching, Germany \\ ${ }^{\mathrm{b}}$ PLANSEE SE, A-6600 Reutte, Austria
}

\begin{abstract}
The high heat flux (HHF) testing of WENDELSTEIN 7-X pre-series target elements is an indispensable step in the qualification of the manufacturing process. A set of 20 full scale pre-series elements was manufactured by PLANSEE SE to validate the materials and manufacturing technologies prior to the start of the series production.

The HHF tests were performed in the ion beam test facility GLADIS. All actively water-cooled elements were tested for about 100 cycles at $10 \mathrm{MW} / \mathrm{m}^{2}$ (10-15 s pulse duration). Several elements were loaded with even higher cycle numbers (up to 1000) and heat loads up to $24 \mathrm{MW} / \mathrm{m}^{2}$. Hot spots were, observed at the edges of several tiles during the HHF tests indicating local bonding problems of the CFC.

The thermo-mechanical behaviour under HHF loading has been evaluated and compared to the FEM predictions. The measured temperatures and strains confirm the chosen FEM approach. This allows a component optimisation to achieve a successful series production of the W7-X divertor target elements..
\end{abstract}

Keywords: WENDELSTEIN 7-X; Divertor; Plasma facing components; HHF tests

* Corresponding author. Tel.: +49 8932991228;

fax: +498932991212.

E-mail address: henri.greuner@ipp.mpg.de (H. Greuner).

\section{Introduction}

The envisaged steady-state operation of W7-X requires the installation of $19 \mathrm{~m}^{2}$ actively water cooled divertor target area [1]. The 890 divertor target elements are made of CuCrZr heat sinks covered with flat tiles of CFC (carbon fibre reinforced composite) NB31 as plasma facing material. The elements are designed to withstand a steady-state heat flux of 10 $\mathrm{MW} / \mathrm{m}^{2}$ and a power load up to $100 \mathrm{~kW}$ for long term plasma operation of W7-X.
The aim of the activities described herein concern the validation of the materials and manufacturing technologies prior to the start of the series production of the target elements by PLANSEE SE. Two different bonding techniques between CFC tiles and heat sink, electron beam welding (EBW) and hot isostatic pressing (HIP), have been evaluated. After the successfully tested CFC front tile bonding [2], a set of 20 full scale pre-series elements (length 250 mm, width 


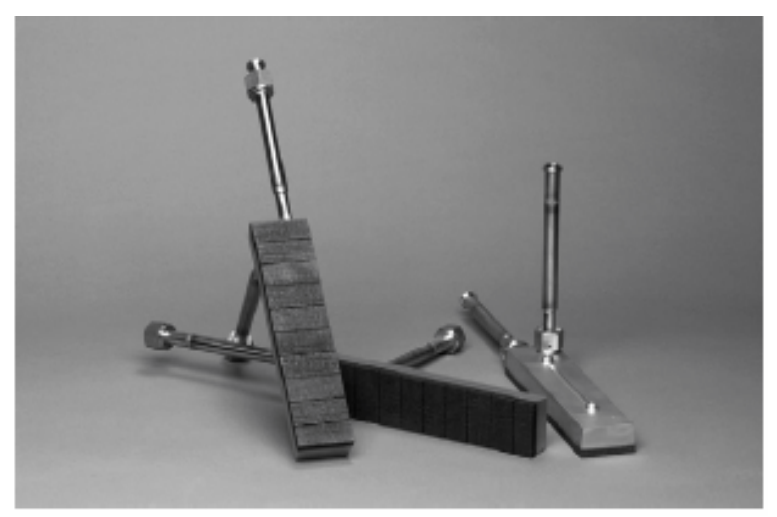

Fig. 1. Photograph of target elements type $4 \mathrm{~S}$ with the cooling water inlet in axial direction and the perpendicular arranged outlet tube. The right hand element shows the 10 flat CFC NB 31 tiles.

$57 \mathrm{~mm}, 10$ flat tiles per element, covered with NB31 from the second batch of the CFC production was produced, Fig. 1 [3]. These elements were tested in the ion beam high heat flux test facility GLADIS [4] in consecutive steps of power loading. At first, a screening at power densities from 6 to $10 \mathrm{MW} / \mathrm{m}^{2}$ and $15 \mathrm{~s}$ duration was performed. Afterwards, all elements were loaded at $10.4 \mathrm{MW} / \mathrm{m}^{2}$ for 80 or more cycles (in the majority of cases for 100 cycles, some up to 1000 cycles) to characterize their fatigue behaviour. Six elements were additionally loaded with $13.5 \mathrm{MW} / \mathrm{m}^{2}$ and 50-100 cycles to evaluate the behaviour at safety factor of 1.3 above the nominal power density. High power loading up to $24 \mathrm{MW} / \mathrm{m}^{2}, 15 \mathrm{~s}$, on three elements completed the evaluation of the thermal performance of the W7-X target design.

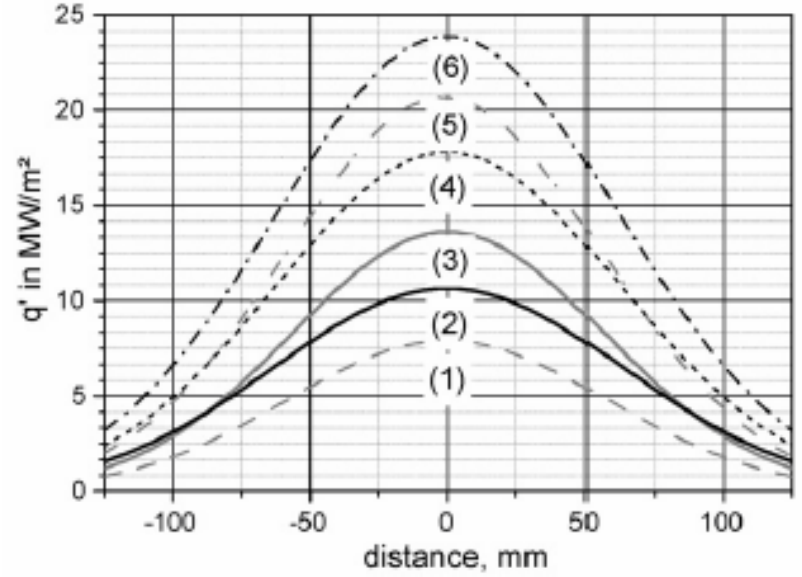

Fig. 2. Fits to measured beam profiles at target position. Three CFC tiles (width $75 \mathrm{~mm}$ ) were loaded within $85-100 \%$ of the central power density on each test position.

\section{Heat loading conditions in GLADIS}

The target elements were installed perpendicular to the ion beam axis in the HHF test facility GLADIS. Three beam positions were used to test the targets with a uniform heat load of $85-100 \%$ of the central heat flux on each tile. The heat load on the end tiles no. 1 and 10 was reduced to $75 \%$ of the nominal heat flux. The power density at the target position was measured and checked with a linearly movable, inertially cooled calorimeter during the test campaign. 2D Gaussian fits to these data provide the beam profiles the target position shown in Fig. 2. Table 1 summarises the applied beam power densities. The comparison between the heat loads measured by cooling water calorimetry of the target and the calculated power input are in a quite good agreement.

Table 1

Comparison of the measured and calculated heat load at the target

\begin{tabular}{llcc}
\hline $\begin{array}{l}\text { Central heat flux } \\
\left(\mathrm{MW} / \mathrm{m}^{2}\right) \text { (profile no.) }\end{array}$ & $\begin{array}{l}\text { Power input calculated from } \\
\text { beam profile }(\mathrm{kW})\end{array}$ & $\begin{array}{l}\text { Power input calorimetrically } \\
\text { measured on target }(\mathrm{kW})\end{array}$ & \begin{tabular}{l} 
Agreement $(\%)$ \\
\hline $8(1)$
\end{tabular} \\
$10.4(2)$ & 62 & $59 \pm 2$ & $95 \pm 3$ \\
$13.5(3)$ & 102 & $82 \pm 2$ & $95 \pm 2.5$ \\
$17.8(4)$ & 144 & $98 \pm 2$ & $95 \pm 2$ \\
$20.5(5)$ & 155 & $137 \pm 3$ & $93 \pm 2$ \\
$24(6)$ & 177 & $144 \pm 3$ & $88 \pm 2$ \\
\hline
\end{tabular}

The measured power input includes the thermal radiation for the profile no. 6 only. 
The cooling water flow of 0.5 and $0.6 \mathrm{l} / \mathrm{s}$ resulted in an axial velocity of 8 and $10 \mathrm{~m} / \mathrm{s}$, respectively. Inserted swirl tapes (twist ratio 4,) in addition to the static pressure of 10 bar and the water inlet temperature of $<20{ }^{\circ} \mathrm{C}$ provide the heat transfer in the forced convection regime up to $10 \mathrm{MW} / \mathrm{m}^{2}$ power load at the target according to the $\mathrm{W} 7-\mathrm{X}$ operating requirements. The following diagnostics were routinely used: watercalorimetry based on a calibrated turbine and PT 100 sensors. For the surface temperature measurements: an INFRATEC IR camera, one- and two-colour pyrometers and a CCD video camera for in situ visual inspection. Ten target elements were identically equipped with thermocouples (TCs) type $\mathrm{K}$ in the CFC, the $\mathrm{Cu}$ interlayer and in the CuCrZr heat sink to measure the thermal response during heat loading and cooling down.

\section{Results of high heat flux tests}

\subsection{Cycles at $10.4 \mathrm{MW} / \mathrm{m}^{2}$}

After the first cycles the elements exhibit homogeneous temperature distribution on all CFC tiles bonded by HIP or EBW in general. The scatter of thermal conductivity of the CFC resulted in an average central surface temperature of all measured tiles of $1115 \pm 90{ }^{\circ} \mathrm{C}$ for the EBW and $1102 \pm 90{ }^{\circ} \mathrm{C}$ for the HIP elements. These temperatures are slightly higher than the 2D FEM calculated surface temperature of $1080^{\circ} \mathrm{C}$.

The optically measured increase of central surface temperature of $50-70{ }^{\circ} \mathrm{C}$ during the cycling was systematically observed for all tested target elements (HIP \& EBW). The same temperature increase was observed for the corresponding TCs located in the CFC tile, in the $\mathrm{Cu}$ interlayer and in the CuCrZr cooling structure as well. This means that the observed surface temperature increase is not due to degradation of the CFC material or of the bonding. Instead, the temperature increase can be traced directly into the heat sink: each measurement location shows the same temperature increase after 50-70 cycles. A relaxation of the elevated temperatures was observed after a loading break of 1-2 days. After the continuation of the loading the above behaviour repeats within 10-20 pulses. Fig. 3 demonstrates this behaviour and shows the summary of measured temperatures for a HIP element. For higher cycle numbers $>200$ no relaxation was observed and the increased temperatures were stable for all measured positions. Presently, the reason for the temperature increase of the cooling structure is not yet clarified. The measured thermal conductivity of the CuCrZr cooling

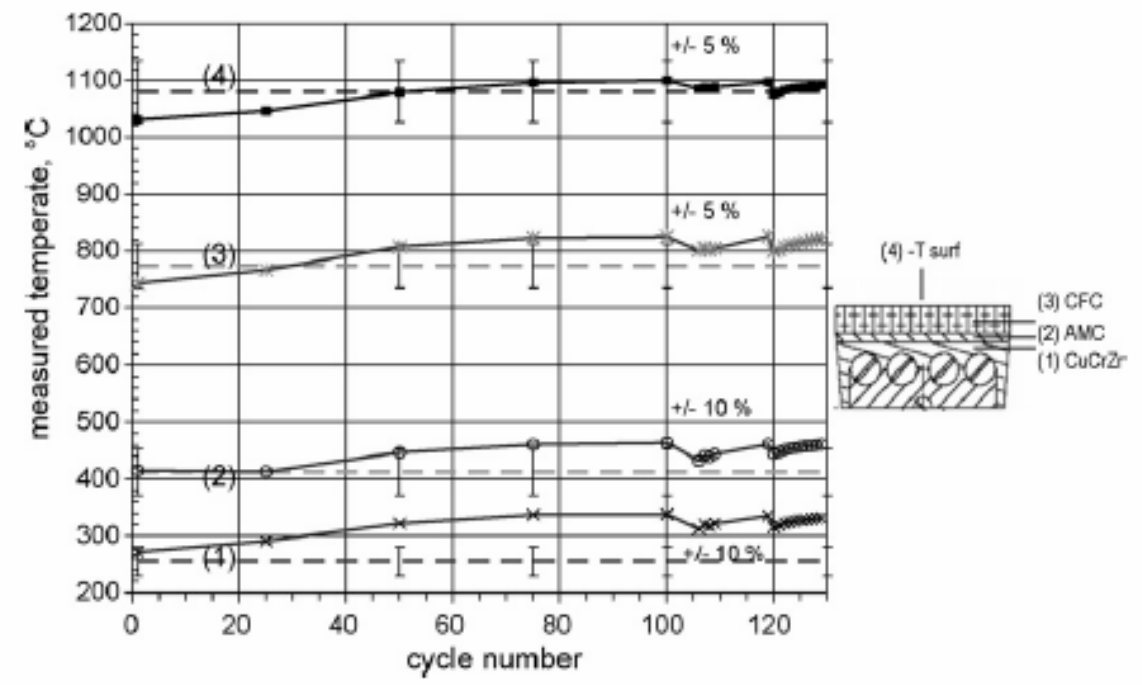

Fig. 3. Measured temperatures during $10.4 \mathrm{MW} / \mathrm{m}^{2}$ cycling of the element 4S-030. The dashed lines mark the expected temperatures obtained from 2D FEM calculation. The position of the TCs (1)-(3) are marked in the cross section. The surface temperature was pyrometrically measured. A break in the loading after cycle no. 100 and 119 resulted in a relaxation of the measured temperatures. 

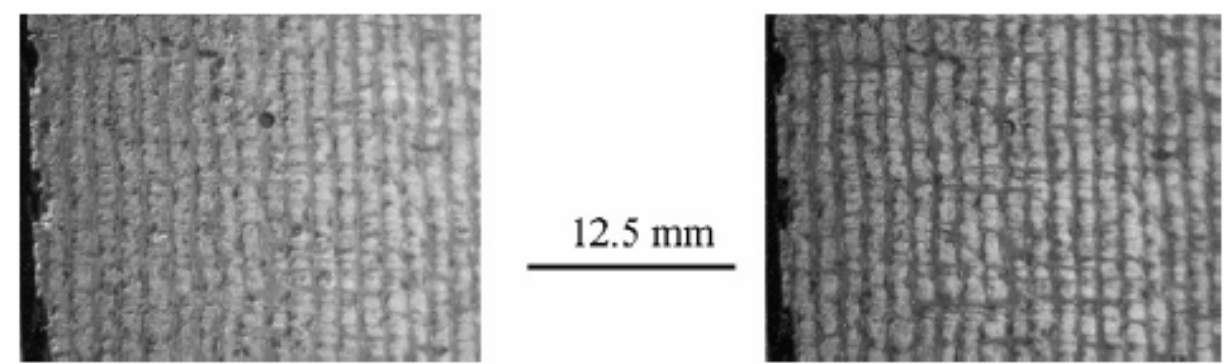

Fig. 4. Micrographs of the central CFC tile, loaded with 1000 cycles $10.4 \mathrm{MW} / \mathrm{m}^{2}, 10 \mathrm{~s}$. The left hand image shows the heat loaded surface after 90 pulses. The distance between the outer edge and the central drilling is $12 \mathrm{~mm}$.

structure did not change after the cycling.

To exclude possible artefacts due to the operation of the test facility or of the diagnostics, the beam parameters and cooling conditions were carefully checked.

- Ion source: constant beam, acceleration voltage and extraction current in an accuracy of $<1 \%$.

- Power load at target: constant calorimetrically measured heat load on the target, $\pm 1.5 \%$.

- Target cooling: constant water velocity and start temperature of the target during cycling, $17.5 \pm 3^{\circ} \mathrm{C}$.

During the first 25 cycles hot spots have been observed on some tiles at the outer edges of CFC tiles, for which indications have been revealed neither by screening in GLADIS below $10 \mathrm{MW} / \mathrm{m}^{2}$ nor by the NDE methods applied at the end of the manufacture [5]. This can be interpreted as a hint for defects below the detection limit of the presently applied NDE methods. Another possibility could be the initiation of defects due to incompletely bonded CFC fibre bundles, which are inclined with respect to the bonding surface at the edge of the tile. Due to the texture of the woven fibre plans, cut fibres without thermal contact to the heat sink generate hot spots at the edge. Which reasons prevail is still under investigation. The IR examination of the 200 loaded tiles after these cycling tests can be summarised as follows. For most tiles (70\%) the surface temperature distribution was homogenous and did not exceed the expected limit. Growing hot spots at the outer edges of CFC tiles are clearly observed on $15 \%$ of the tiles. For the remaining $15 \%$ the observed hot spots are relatively stable or the temperature increases are low and it is difficult to distinguish between CFC inhomogeneities or growing bonding defects.

\subsection{0 cycles at $10.4 \mathrm{MW} / \mathrm{m}^{2}$}

The central parts of two elements (HIP \& EBW) were loaded with 900 additional cycles according to the parameters described in paragraph 3.1. In situ microscopy of the loaded CFC surface was undertaken supplementary to the IR observation. Fig. 4 shows

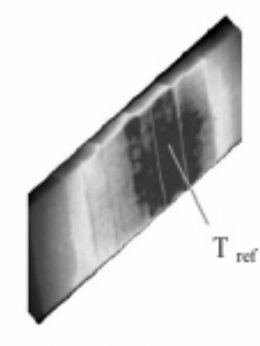

IR image after pulse 80

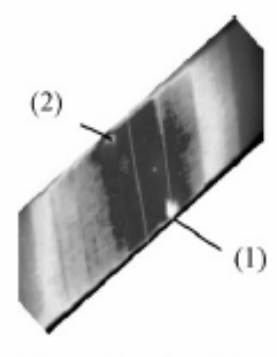

IR image afler pulse 1000

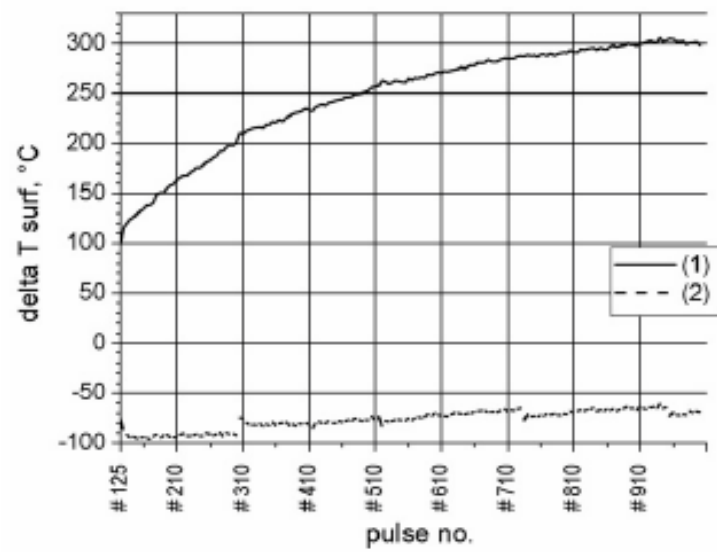

Fig. 5. The upper two IR images show the surface temperature after pulse number 80 and 1000. The measured temperature development of the two hot spots (1) and (2) shown in the graph is related to the central temperature $T_{\text {ref }}$ of tile 5 . 
images after the pulse 90 and 1000 without any cracks, delaminations or erosion after the loading. No degradation of the morphology of the loaded CFC surface was observed.

Compared to the result of the 100 cycle loading, no new defects occurred. Existing tile edge defects were growing. The measured average tile temperatures were stable. Fig. 5 shows the measured surface temperatures at different tile edges during cycling. The reference of the temperature increase is the central temperature of tile 5, where the beam centre is located. The central loaded tile 5 did not show any hot spots. The temperature increase at the lower left edge of tile 4 indicates a growing bonding defect. The temperature increase of the upper corner of tile 6 is low and seems relatively

stable.

\subsection{Cycling at $13.5 \mathrm{MW} / \mathrm{m}^{2}$}

Following the above-mentioned cycling, 21 tiles of 6 elements have been successfully loaded with 50 cycles $13.5 \mathrm{MW} / \mathrm{m}^{2}, 10-15 \mathrm{~s}$ duration and $10 \mathrm{~m} / \mathrm{s}$ water flow. The measured temperatures of the loaded tiles are in a good agreement with the results from 2D FEM ANSYS calculation:

- Surface temperature, pyrometrically measured $1506^{\circ} \mathrm{C}\left(1480{ }^{\circ} \mathrm{C} \mathrm{FEM}\right)$.

- CFC temperature, TC measured $985{ }^{\circ} \mathrm{C}\left(1005{ }^{\circ} \mathrm{C}\right.$ FEM).

- Cu interlayer, TC measured $457^{\circ} \mathrm{C}\left(505^{\circ} \mathrm{C}\right.$ FEM).

- CuCrZr cooling structure, TC measured $316{ }^{\circ} \mathrm{C}$ $\left(295^{\circ} \mathrm{C}\right.$ FEM).

The temperature at the critical outer edge of $\mathrm{CFC} / \mathrm{Cu}$ bonding increased from 550 to $680{ }^{\circ} \mathrm{C}$ compared to the $10.4 \mathrm{MW} / \mathrm{m}^{2}$ loading. Nevertheless after these tests only one new defect on a tile edge was observed. Sixteen tiles survived without any visible defects. The existing defects on four tiles were growing slowly.

\subsection{High power loading up to $24 \mathrm{MW} / \mathrm{m}^{2}$}

Two elements, cycled with $13.5 \mathrm{MW} / \mathrm{m}^{2}$ before, were successive loaded with $15 \mathrm{~s}$ pulses up to $24 \mathrm{MW} / \mathrm{m}^{2}$ to explore the thermal performance of the W7-Xtarget design. The water-cooling with $10 \mathrm{~m} / \mathrm{s}$ and 10 bar static pressure was sufficient to guarantee the stable heat exchange in the subcooled boiling regime. The absorbed power in the cooling water is $147 \mathrm{~kW}$ and the thermal radiation of the CFC surface is approximately 8 $\mathrm{kW}$. The surface temperature exceeded $2500^{\circ} \mathrm{C}$ and the measured $\mathrm{CFC} / \mathrm{Cu}$ interlayer temperature was close to the expected melting point. CFC tiles without previous defects withstood 6-8 loadings before the typical edge defect started. Existing defects are growing fast and resulting in a strong overheating and erosion of the CFC.

Based on the strong light emission of such highly loaded CFC tiles it should be possible to detect such overloading of targets in the operation of W7-X. The maximum allowed temperature for the $\mathrm{CFC} / \mathrm{Cu}$ interlayer without melting will be reached after $6 \mathrm{~s}$ loading. Within this time the overloading has to determined during W7-X discharges in order to avoid damage of the target elements.

\section{Analysis of the thermo-mechanical behaviour}

Due to the large mismatch in the coefficients of thermal expansion for CFC and CuCrZr - resulting in high residual stresses as well as high operationinduced stresses - the bonding zone between CFC and $\mathrm{Cu}$ is generally the most critical issue for the operational behaviour of the target elements. To achieve a sufficiently high manufacturing quality together with a high lifetime during operation the heat loading tests of pre-series elements were performed in combination with extensive FEM analyses. Therefore, a programme of fully 3D non-linear thermo-mechanical FEM calculations was started to evaluate the behaviour of the target elements with a special focus on the optimization of the stress situation in the bonding zone between the CFC and the CuCrZr heat sink [6]. The calculated surface temperatures, global deformations, and strains are compared to experimentally measured data during high heat flux tests to verify the FE model. In particular, the 3D finite element model includes the thermal and mechanical loading and boundary conditions as given at the GLADIS test facility.

Based on the experimentally confirmed model, the finite element analysis allowed to optimize the detailed target design for the expected operational conditions in W7-X. 


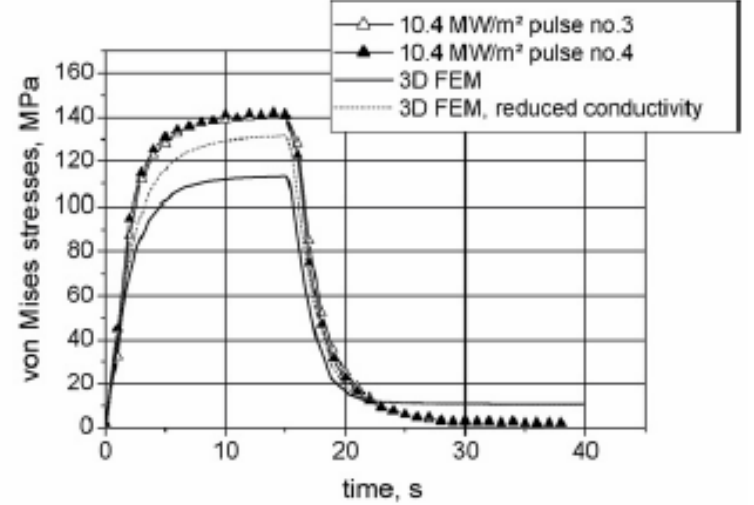

Fig. 6. Comparison of measured and FEM calculated stresses. The strains were measured at the back plate during two pulses of $15 \mathrm{~s}$ heating. The full line shows the predicted evolution of von Mises equivalent stresses at the position of the strain gage arrangement at the back plate of the target element. The dashed line demonstrated the effect of a $25 \%$ reduced thermal conductivity of the heat sink material.

\subsection{Strain gauge measurements}

Strain gauge rosettes bonded onto the CuCrZr back plate of the central part of the target elements were used for the dynamic deformation and stress analysis under heat load.

Rosettes of type CEA-09-125UR-350 (manufacturer Vishay) were arranged in three-wire quarter bridge circuits. Temperature sensors ETG 50A/E close to the strain gages were used to compensate the thermal output signal of the strain gages. The strains and the temperature are recorded with a sample rate of $1 \mathrm{~Hz}$. Two different types of target elements were equipped with two rosettes each. The increases of the measured elastic thermal strains during the cycling are based on the temperature increase of the cooling structure described in paragraph 2.1. Fig. 6 shows the von Mises equivalent stresses calculated from the measured strains in the case of two pulses $10.4 \mathrm{MW} / \mathrm{m}^{2}$ and $15 \mathrm{~s}$ heating. The strains are in the elastic region and nearly fully developed after $8 \mathrm{~s}$ heating. The measured strains are comparable. This result confirms that a pulse duration of $10 \mathrm{~s}$ for the cyclic loading tests is sufficient to reach a thermo-mechanical equilibrium during the heat loading.

The good agreement of the experimentally measured stresses and the global FEM results is an important basis for the further optimization of the manufacturing route.

4.2. Comparison of results obtained via experiments and finite element analyses

In general, the FEM-based simulations of the target element aim at predicting the temperatures, stresses, strains, and corresponding measures under operational loading in order to extract an optimum parameter set with respect to geometrical design and material parameters, respectively (see [5]). In the present work special attention is being paid to the temporal evolution of the calculated von Mises equivalent stresses and strain components at the back plate of the heat sink and their evaluation with respect to the corresponding experimental results. The FEM-model accounts for symmetry conditions in the geometrical design and the heat flux loading profile, i.e. only one quarter of the full target element is modelled. Furthermore, temperature dependent film conditions and a constant coolant pressure of 10 bar are accounted for the free surface of the coolant channels. Additionally, a constant coolant temperature of $20^{\circ} \mathrm{C}$ is assumed. The metallic material sections of the target element, i.e. the AMC-Cu section and the $\mathrm{CuCrZr}$ section, are assigned with temperature dependent thermo-elasto-plastic material characteristics. The CFC-section makes use of a temperature dependent orthotropic thermo-elastic material description. In particular, the mechanical behaviour of CFC is modelled via an orthotropic non-linear elastic constitutive law that incorporates evolution equations for internal variables in terms of damage relevant parameters thus allowing to describe the non-linear stress-strain characteristics for the individual principal material directions under normal tensile and compressive loading, respectively, as well as under shear loading in the principal material planes. The simulations are carried out with the FEM-package ABAQUS/Standard V.6.5 [7].

The maximum von Mises stress at the free edge of the target element does not exceed $135 \mathrm{MPa}$.

The calculated evolution of the von Mises equivalent stress evaluated at the position of the strain gauges at the back plate of the target element is included in Fig. 6 . The result at this location at the back plate is in a reasonable agreement with the experimentally obtained 
results. The slightly lower calculated thermal stress values can be explained with the differences of coolant temperature between experiment and computation or variations of the assumed material properties. A 25\% reduced thermal conductivity of the CuCrZr cooling structure resulted in an increase of the von Mises equivalent stress of 20MPa for example.

\section{Conclusions}

The HHF tests of a set of 20 full scale target elements with heat loads similar to the expected operating conditions were performed in the ion beam test facility GLADIS.

After the $10 \mathrm{MW} / \mathrm{m}^{2} \mathrm{HHF}$ loading with 100 cycles of 20 elements (200 tiles) 70\% of CFC tiles did not show any defects. No tile detachment occurred, but several hot spots at the outer edges of tiles indicate bonding problems between CFC and AMC interlayer. Locations are often visible after a few cycles. These growing hot spots prove that 20-100 thermal cycles are a good base to examine the quality of the CFC tiles and of the bonding to the component.

The observed increase of CFC and AMC temperatures are caused by an increase of CuCrZr heat sink temperature during cycling. Except for the local bonding problems no degradation of the CFC material or of the bonding was detected.

The results of the $13.5 \mathrm{MW} / \mathrm{m}^{2}$ cycling tests and the screening up to $24 \mathrm{MW} / \mathrm{m}^{2}$ demonstrate the reliability and the sufficient "heat load safety margin" of this target concept.

The good agreement of measured temperatures and strains compared to the predictions of the3Dnon-linear FEM calculations confirm the chosen FEM approach. This allows an effective component optimization to achieve a successful series production of the W7-X divertor target elements.

\section{References}

[1] H. Renner, D. Sharma, J. Kißlinger, J. Boscary, H. Grote, R. Schneider, Physical aspects and design of the W7-X divertor, Fusion Sci. Technol. 46 (2) (2004) 318-326.

[2] H. Greuner, B. Boeswirth, J. Boscary, P. McNeely, High heat flux facility GLADIS—operational characteristics and results of W7-X pre-series target tests, Journal of Nuclear Materials 367-370 (2007) 1444-1448

[3] J. Boscary, H. Greuner, K. Scheiber, B. Streibl, B. Schedler, J. Schlosser, Results of the examinations of the W7X pre-series target elements, Fusion Eng. Des. 82 (2007) 1634-1638.

[4] H. Greuner,H. Bolt, B.B"oswirth, T. Franke, P. McNeely, S. Obermayer, et al., Design, performance and construction of a 2 MW ion beam test facility for plasma facing components, Fusion Eng. Des. 75-79 (2005) 345-350.

[5] M. Missirlian, H. Traxler, J. Boscary, A. Durocher, F. Escourbiac, J. Schlosser, B. Schedler, P. Schuler, Infrared thermography inspection methods applied to the target elements of W7-X divertor, Fusion Engineering and Design 82 (2007) 1747-1755

[6] A. Plankensteiner, A. Leuprecht, B. Schedler, K.-H. Scheiber, H. Greuner, Finite element based design optimization of WENDELSTEIN7-X divertor components under high heat flux loading, Fusion Engineering and Design 82 (2007) 1813-1819

[7] ABAQUS V.6.5, Abaqus Inc., Providence, RI, 2005. 